\title{
CORRELAÇÃO DA FADIGA TÉRMICA ENTRE SIMULAÇÃO E TESTE DE BANCADA PARA CASOS TRANSIENTES EM TROCADORES DE CALOR.
}

\author{
João Paulo Sparvoli da Silva; Rodrigo Lucio; Edison Tsutomu Miyauchi; \\ Helio Mamoru Nakamura.
}

MAHLE Behr Gerenciamento Térmico do Brasil Ltda.

E-mails: joao.sparvoli@br.mahle.com, rodrigo.lucio@br.mahle.com, edison.miyauchi@br.mahle.com, helio.nakamura@br.mahle.com.

\section{RESUMO}

Este trabalho tem como o intuito de desenvolver e validar uma metodologia para simulação da fadiga causada pela variação da temperatura em um trocador de calor durante regimes transitórios utilizando simulações CFD e FEA.

Após a simulação colocamos as mesmas condições de contorno em bancada para validar experimentalmente os resultados obtidos. Assim, conseguimos gerar propostas de design e material para:

- evitar quebras por fadiga causada pelo choque térmico;

- reduzir o tempo e custo de desenvolvimento e validação de um produto;

- explorar e/ou validar ideias para otimização e redução de custos de um produto.

Estes fatores associados se tornam fundamentais em uma indústria cada vez mais competitiva, focada em qualidade, inovadora e sem margem para erros.

\section{INTRODUÇÃO}

Com o intuito de diminuir cada vez mais o impacto que os veículos comerciais causam no meio ambiente os fabricantes de caminhões e ônibus vem desenvolvendo tecnologias para reduzir ainda mais o consumo de combustível e a emissões de gases e quantidade de partículas.

Os sistemas de gerenciamento térmico nos motores assume uma função relevante, uma vez que para reduzir as emissões os veículos requererão uma maior dissipação 
térmica, que por sua vez provocarão gradientes de temperatura mais elevados, causando uma maior fadiga térmica nos trocadores de calor.

\section{SISTEMA DE ARREFECIMENTO PARA NOVAS NORMAS DE EMISSÕES.}

Com as novas legislações que restringem as emissões de poluentes. confirmou-se a tendência de que a maioria das soluções utiliza a combinação de refrigeradores de gás de exaustão EGR (Exhaust Gas Recirculation) com sistema de pós-tratamento SCR (Selective Catalytic Reduction) [1]. Isto implica em requisitos mais rigorosos para o sistema de arrefecimento, tais como:

- Altas temperaturas e pressões no sistema de arrefecimento;

Os trocadores de calor têm que suportar as variações de pressão no sistema de arrefecimento que aumentaram devido às novas bombas de água e compressores mais potentes; temperaturas mais altas resultado de um aumento na carga térmica que os motores de nova geração estão expostos.

- Aumento da rejeição térmica no sistema;

Os novos refrigeradores EGR tem de rejeitar até $100 \mathrm{~kW}$ que serão transferidos para os trocadores de calor e por sua vez para o ambiente.

O aumento da temperatura na câmara de combustão revelou uma melhora na eficiência da combustão, com consequentes benefícios para o consumo e nível de emissões. Em contrapartida, o sistema passou a rejeitar mais calor para o sistema de arrefecimento

- Temperaturas do ar de admissão e pressões mais elevadas

O uso de EGR provoca um aumento nas pressões do ar em até $12 \%$ e na temperatura por volta de $20 \%$. Isso resulta uma carga adicional sobre os trocadores de calor.

Levando em conta o que mencionamos anteriormente é importante verificar o impacto causado por esses novos fatores no sistema de arrefecimento, principalmente no que se refere a fadiga térmica já que as temperaturas aumentam cerca de $20 \%$.

\section{FADIGA TÉRMICA}

A fadiga pode ocorrer por esforços cíclicos oriundos de um carregamento variável ou variações de temperatura. Esse carregamento pode ser de amplitude e frequência constante ou variável. A fadiga térmica é encontrada quando temos uma flutuação da temperatura que causa esforços internos proporcionados pela anisotropia da expansão térmica que provoca uma falha. Mudanças de temperatura no fluido causam gradientes de temperaturas na seção fazendo com que a expansão térmica natural do material provoque um gradiente de tensão no mesmo. A restrição à expansão em um sentido é um resultado direto da continuidade do meio. Quando 
isso ocorre temos tensões térmicas resultado dessa variação térmica (Figuras 1 e 2) [2, 3 e 4].

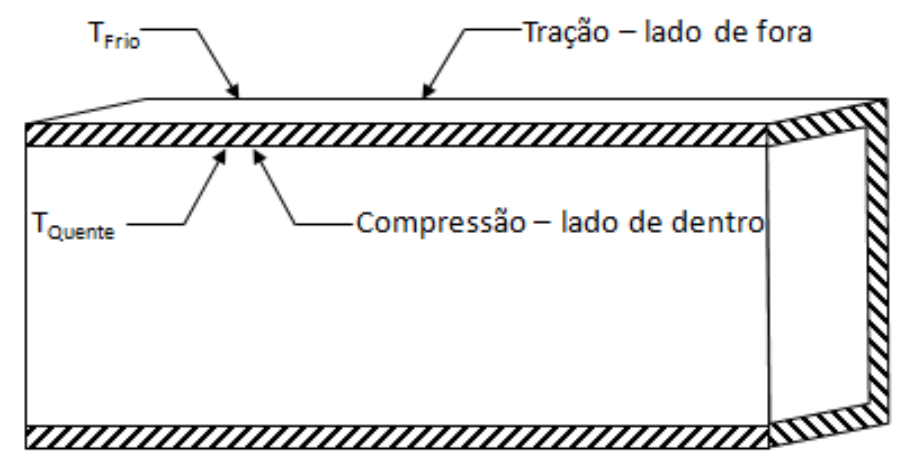

Figura 1 - Efeito da restrição local dentro da tubulação.

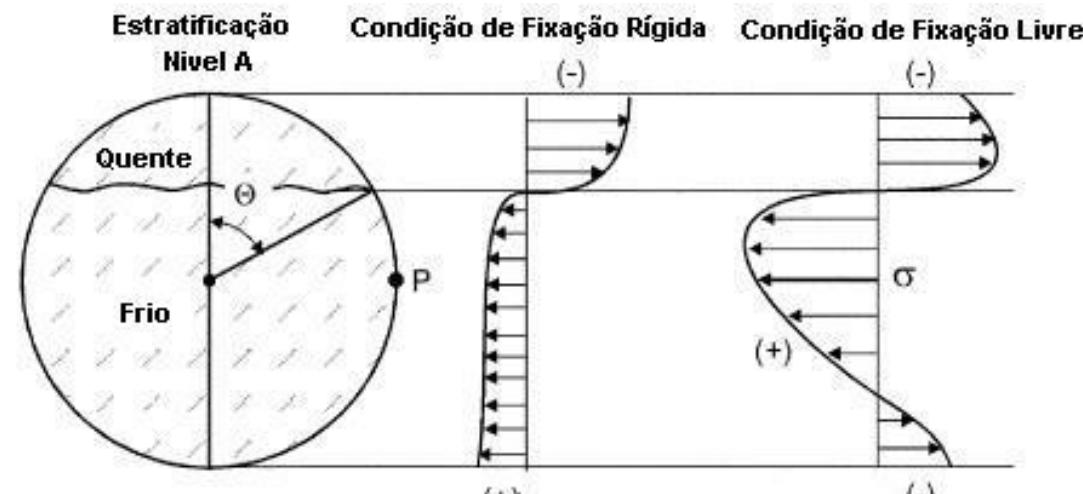

$(+)$

$(-)$

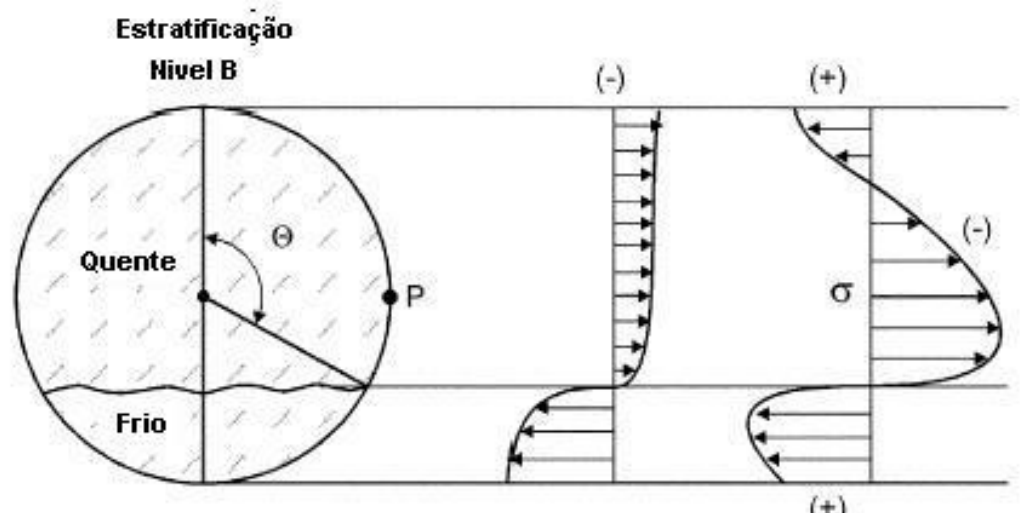

Figura 2 - Efeito da restrição local dentro da tubulação. [2]

Pode-se definir a fadiga térmica como: "Uma deterioração gradual e eventual trincamento de um material pelo aquecimento alternado ao resfriamento, durante expansão térmica livre ou confinada parcialmente ou completamente" (Alvarenga, apud Spera) [2]. Tem-se uma variação cíclica de tensão mecânica, considerando as 
tensões por confinamento, o fenômeno de deterioração gradual e eventual trincamento de um material se dá por Fadiga Termomecânica [2] (Figuras 3, 4, 5 e $6)$.

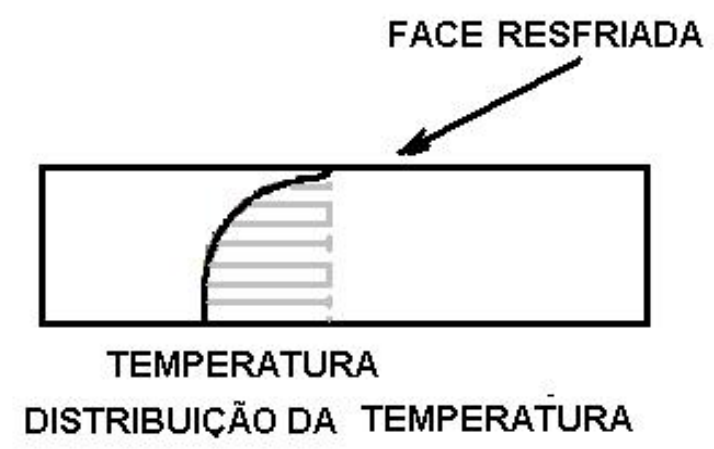

Figura 3 - Perfil da variação de temperatura em uma chapa ou parede de tubulação submetida à Fadiga Termomecânica. [2].

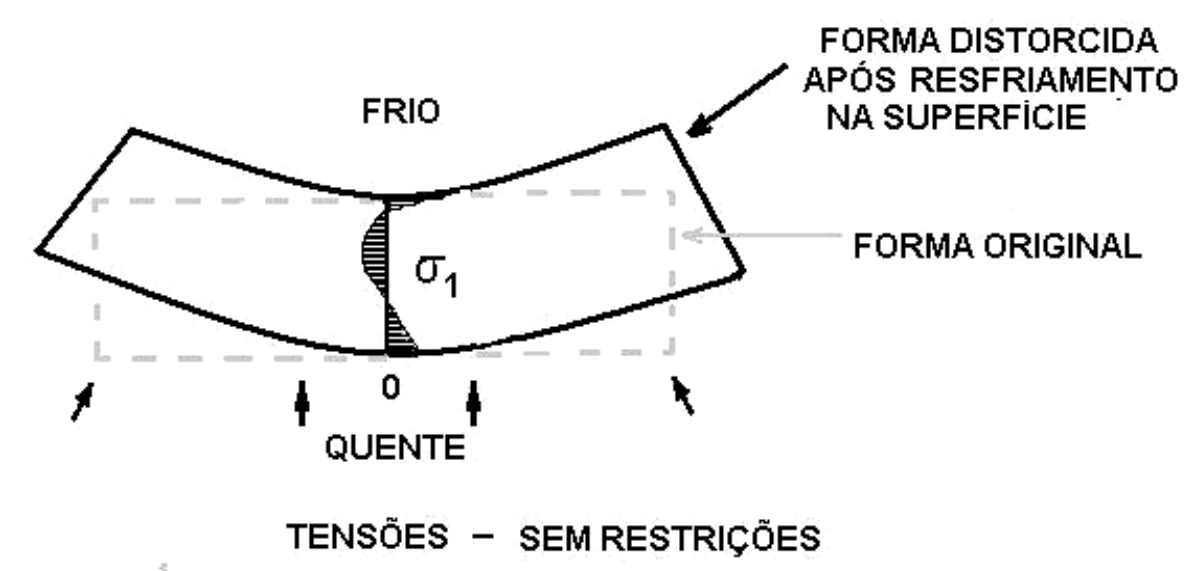

Figura 4 - Distribuição de tensões em uma chapa ou parede de tubulação submetida a variações de temperatura sem restrições externas. [2]

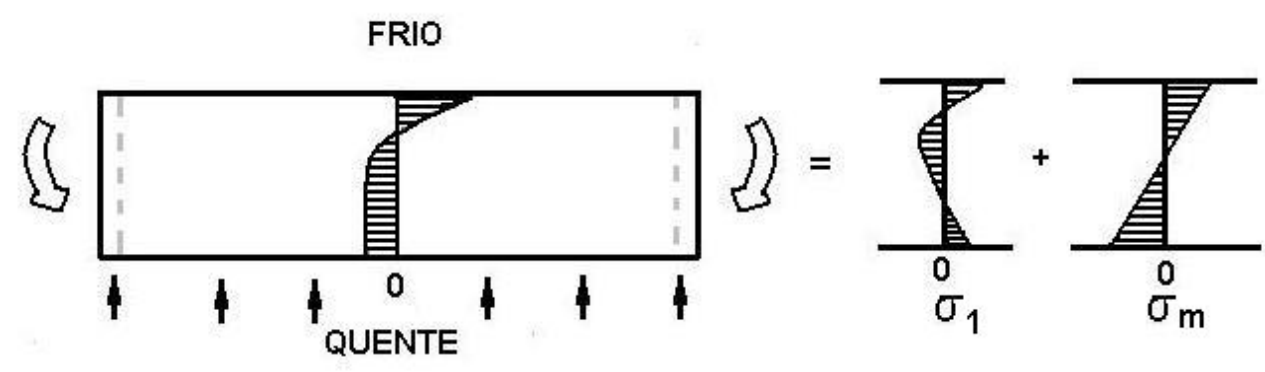

TENSÃo - RESTRIÇÃO DE CURVATURA

Figura 5 - Distribuição de tensões em uma chapa ou parede de tubulação submetida a variações de temperatura com restrições externas de curvatura. [2] 


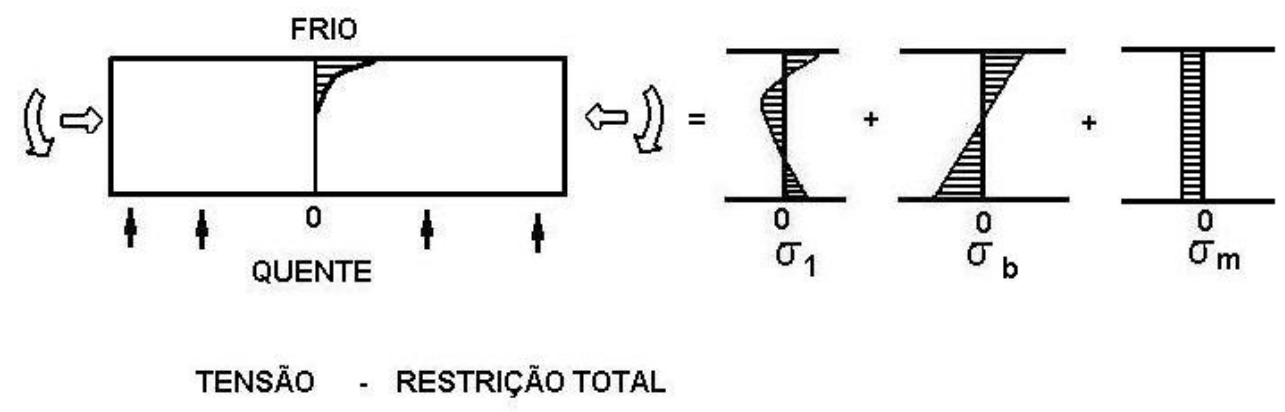

Figura 6 - Distribuição de tensões em uma chapa ou parede de tubulação submetida a variações de temperatura com restrições externas totais. [2]

Normalmente tem-se também cargas mecânicas aplicadas juntamente com cargas térmicas. Estas podem ser Em-Fase ou Fora-de-Fase (Figura 7), dependendo se a carga mecânica é aplicada quando a temperatura sobe ou desce [2]. Isso claramente pode antecipar, caso ocorra uma ciclagem Fora-de-Fase, ou postergar, caso tenha-se Em-Fase, o aparecimento de uma trinca no material.

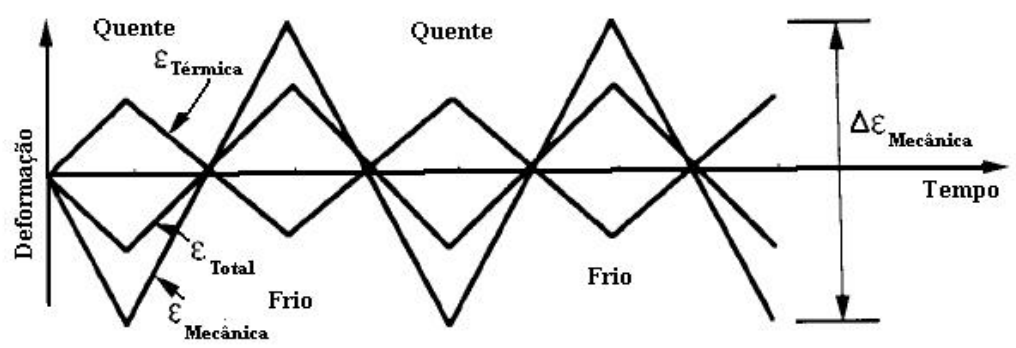

FORA-DE-FASE

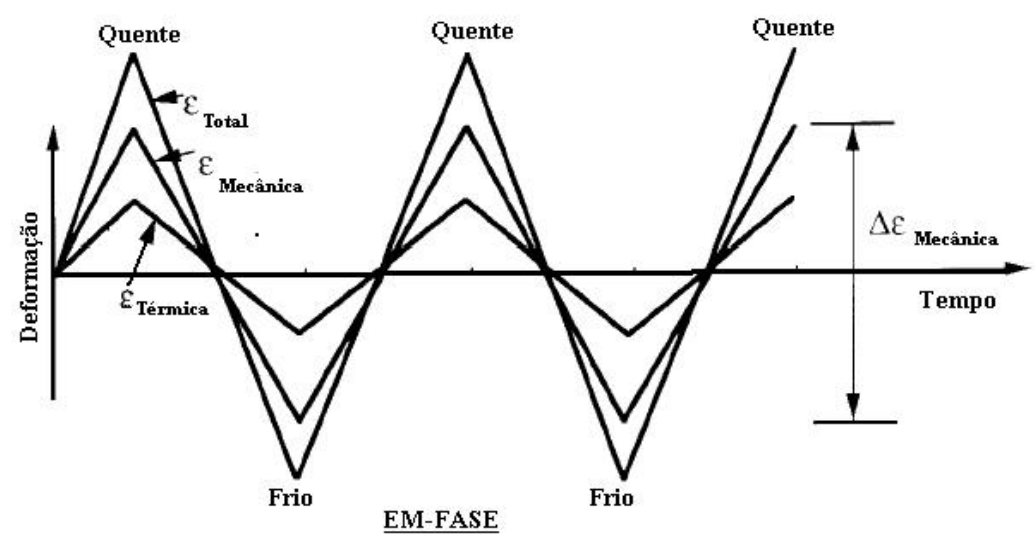

Figura 7 - Gráfico das tensões em função do tempo. [2]

A região onde ocorre a maior variação de tensões é nos tubos dos radiadores de ar do motor (Figura 8), onde tem-se uma variação constante de temperatura e pressão provenientes dos diferentes regimes de funcionamento da turbina causadas pela forma de utilização de um veículo seja nos centros urbanos ou rodovias. 


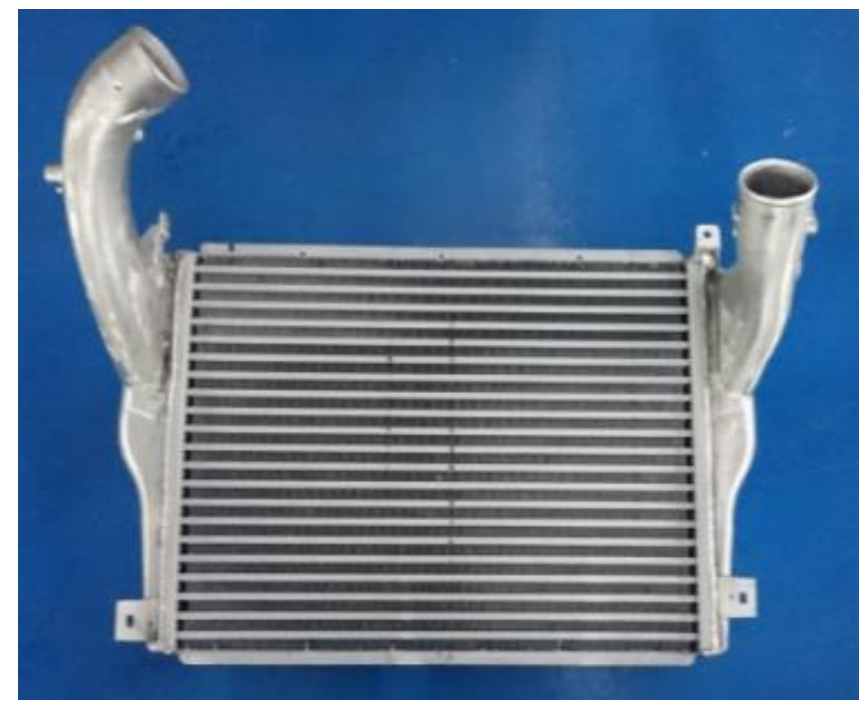

Figura 8 - Radiador de ar.

Atualmente não temos uma curva de tensão x número de ciclos para a geometria de trocadores de calor onde contemplaria também o fator de temperatura, mas sabemos que o seu comportamento é exponencial (Figura 9) e que depois de $10^{6}$ ciclos é considerado como vida infinita.

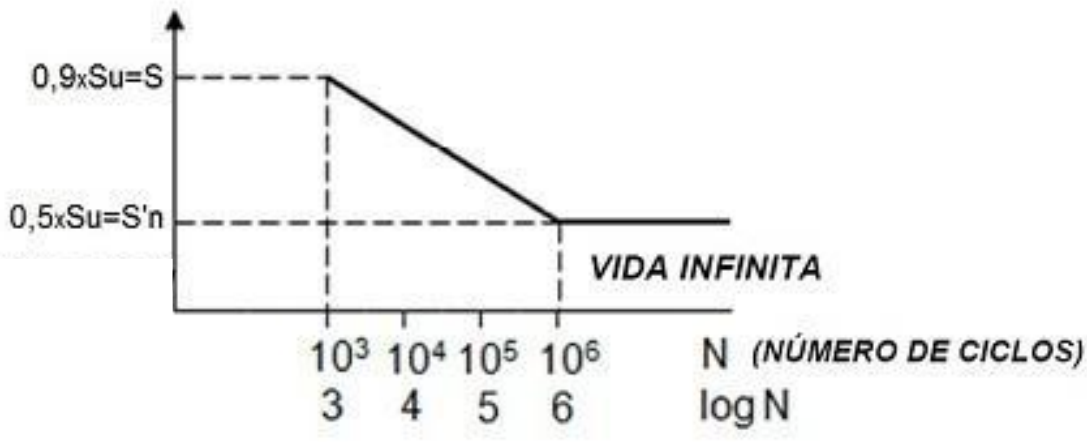

Figura 9 - Diagrama S-N típico

\section{METODOLOGIA}

Esse trabalho está dividido em 4 partes:

- Definição das condições de contorno;

- Modelagem e simulação do trocador de calor;

- Testes em bancada;

- Analise dos resultados.

Que são detalhados a seguir.

3.1. Definição das condições de contorno 
Para a determinação das condições de contorno do sistema a ser estudado escolheu-se um veículo comercial que tem a aplicação urbana. Essa aplicação foi escolhida já que o mesmo se encontra em constante variação de temperaturas e pressões em seu sistema de arrefecimento sendo assim uma condição mais critica para o nosso estudo.

Foram coletados os dados de pressão e temperatura (Figura 10 e 11) da entrada e saída do radiador de ar durante um trecho urbano simulando as paradas constantes que o veículo teria durante o seu funcionamento diário.

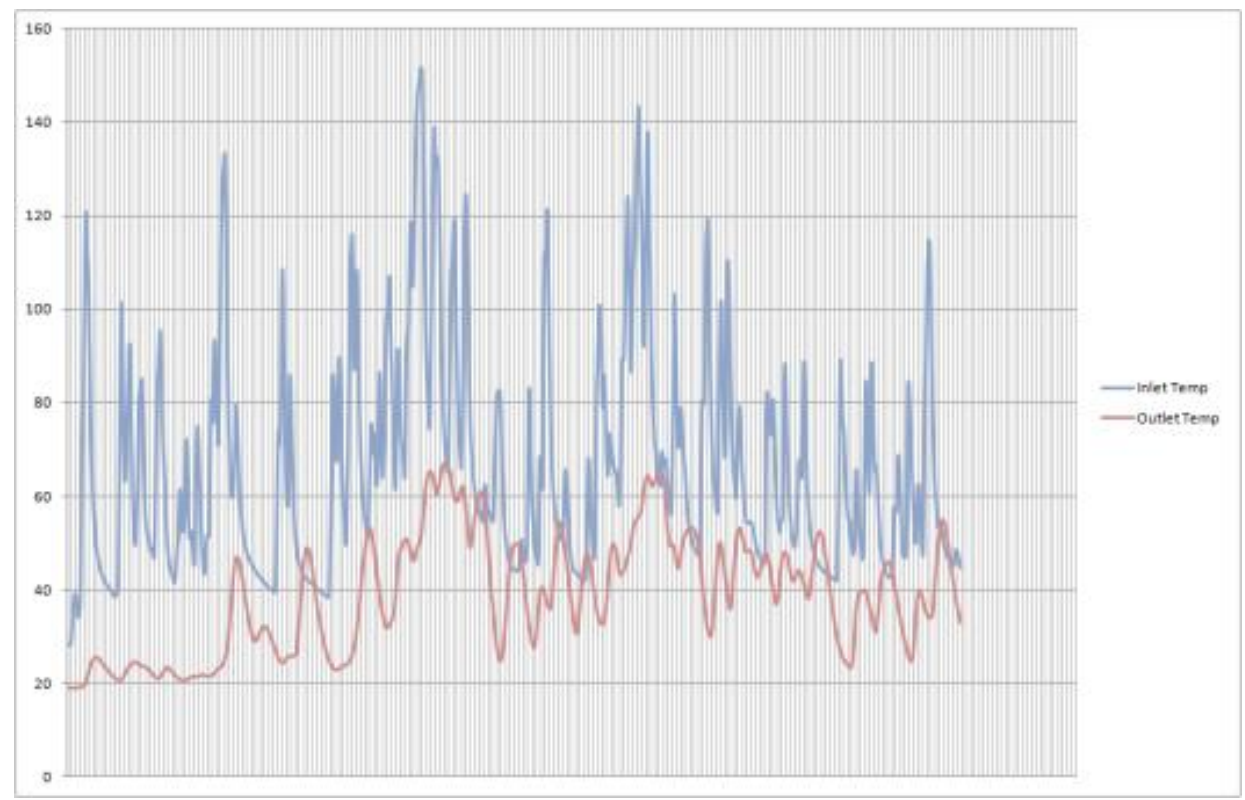

Figura 10 -Gráfico do perfil de temperatura na entrada e saída do radiador de ar em função do tempo.

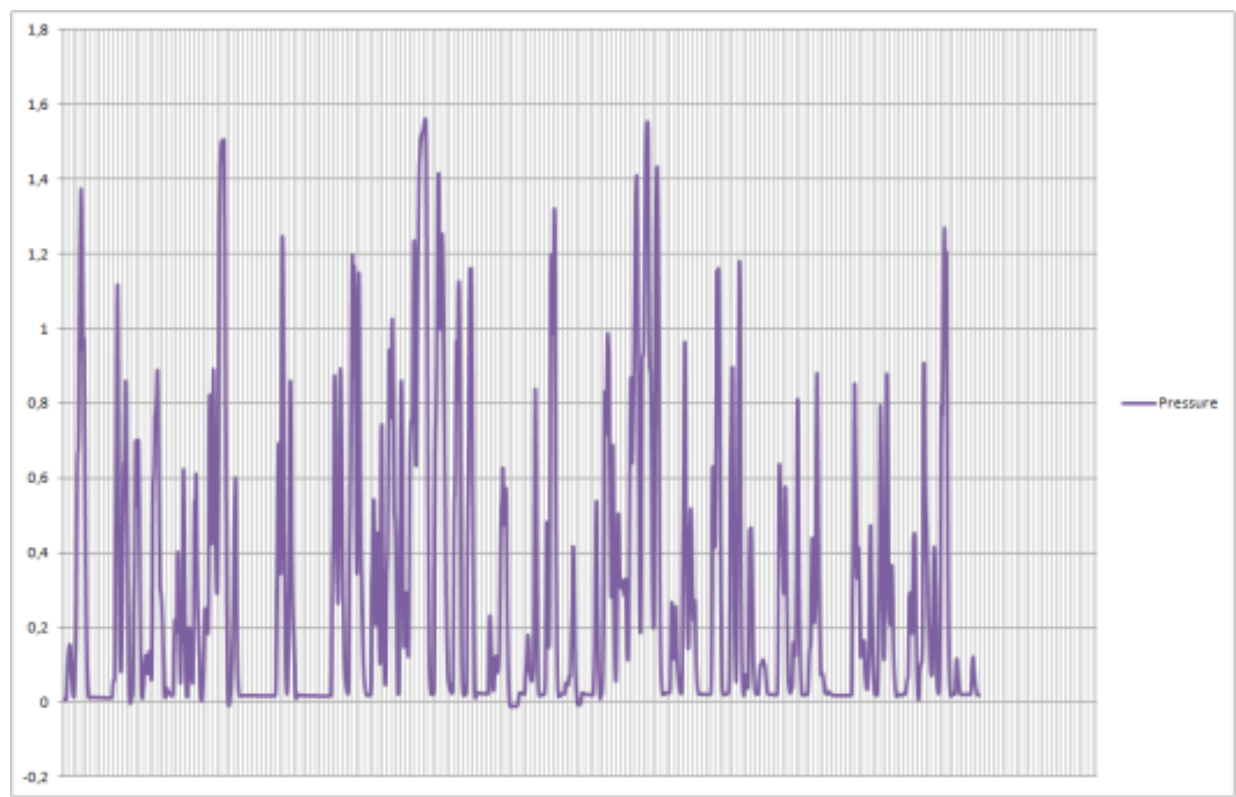

Figura 11 - Gráfico do perfil de pressão na entrada do radiador de ar em função do tempo. 
Ponto de medição de Temperatura e pressão de entrada

Ponto de medição de

Temperatura e pressão de saída

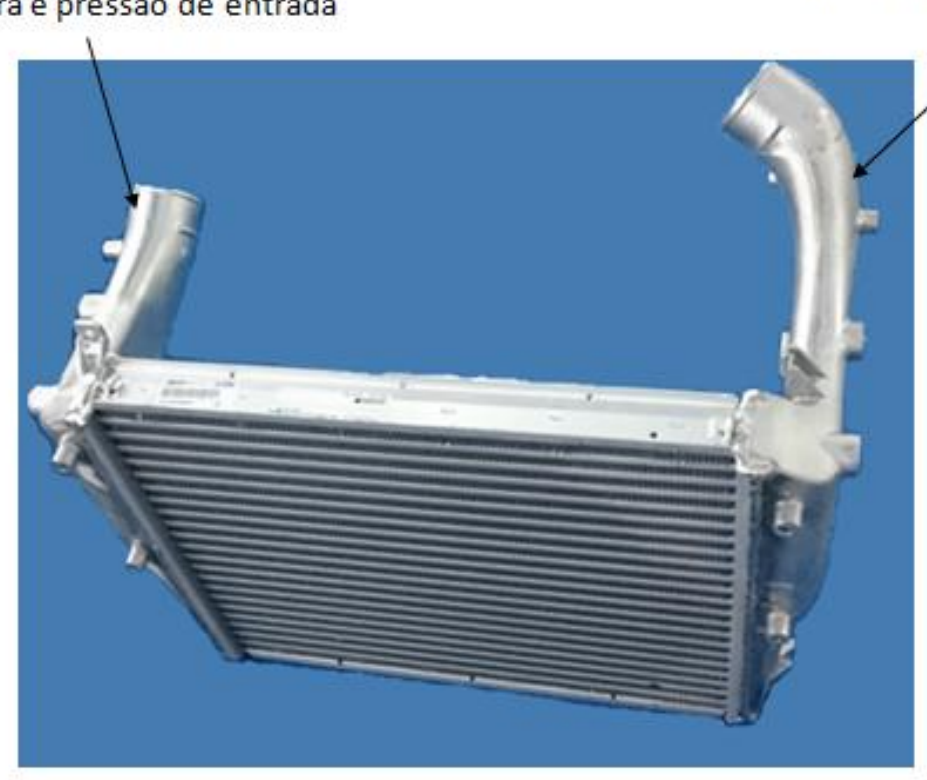

Figura 12 - Pontos de coleta de pressão e temperatura.

Com base nos resultados apresentados anteriormente definiu-se o perfil de temperatura, vazão (Figura 13) e também uma pressão constante de 1,6 bar na entrada da peça.

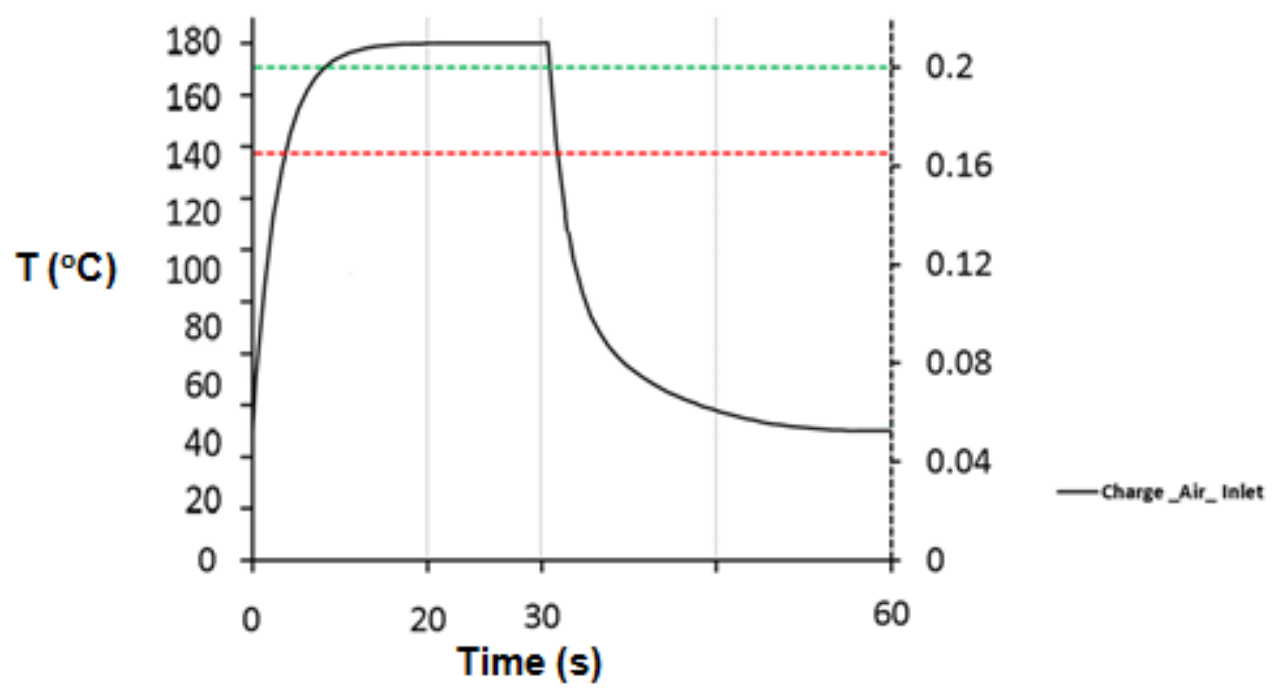

Figura 13 - Perfil de temperatura e vazão em função do tempo.

3.2Modelagem e Simulação.

A maior dificuldade que se encontra para fazer esse tipo de simulação é o fato do sistema estar sempre em regime transiente, com isso tem-se uma temperatura 
diferente em cada instante de tempo. Para que se possa encontrar esse perfil de temperatura utiliza-se a análise de dinâmica de fluidos computacional - CFD. Após isso podemos analisar as tensões resultantes devido à dilatação térmica e os esforços no componente utilizando a analise de elementos finitos - FEA.

Para a simulação foram feitas quatro propostas diferentes com o intuito de definir a melhor para a aplicação e correlacionar com os testes físicos.

O modelo foi elaborado através do software de modelagem Medina-pré versão 8.4.1 utilizando uma combinação de elementos sólidos TETRA10, HEXA8, QUAD4 com um total de 1618099 nós e 1103704 elementos.

Para o calculo foi utilizado o software PERMAS versão 15.00.112, para a analise de CFD foi utilizando o Star CCM + versão v10.02.

Para as condições de contorno da peça foram considerados os mesmos pontos de fixação da bancada (Figura 20), que são os mesmos pontos de fixação do radiador de ar e o radiador de água.

\subsubsection{Proposta 1-Peça base.}

Essa proposta seria uma peça base, sem aplicação de nenhuma técnica para redução das tensões durante a sua operação. Um trocador meio ar-ar onde se tem um grande gradiente de temperatura.

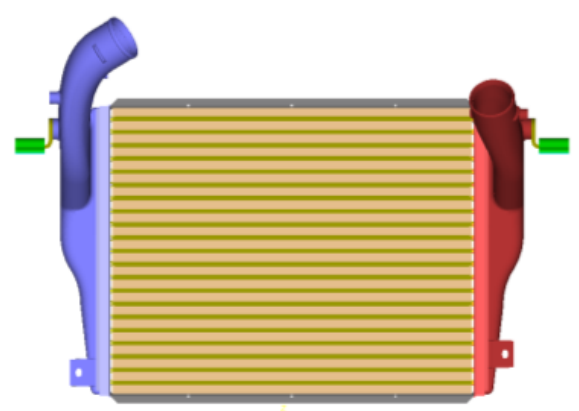

Figura 14 - Modelo 3D do trocador de calor usado durante o desenvolvimento.

Os resultados obtidos da variação de tensão é apresentado abaixo. Onde é possivel verificar que as maiores tensões se encontram nos tubos da parte superior do lado mais quente.

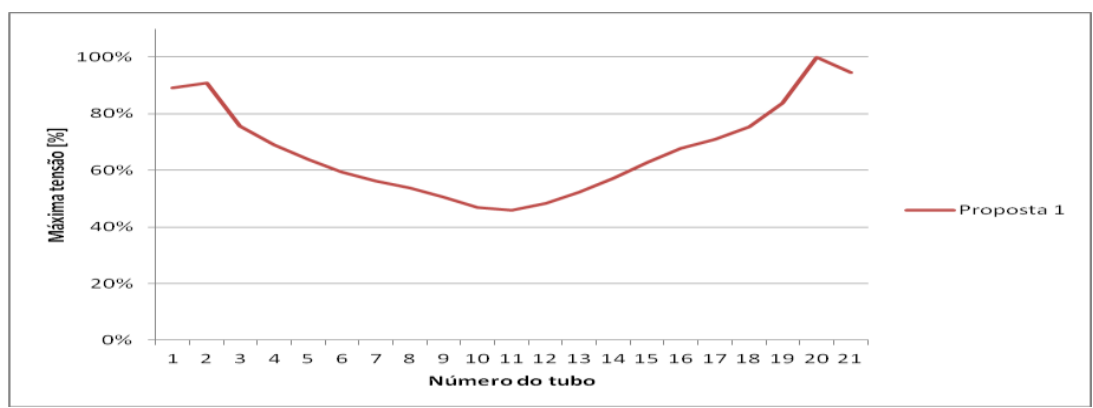

Figura 15 - Perfil da variação de tensões máximo encontrado no trocador. 
3.2.2. Proposta 2 - Permitir a dilatação térmica nos tubos.

Com uma mudança na geometria do suporte lateral do trocador de calor proporcionamos mais liberdade na dilatação térmica dos tubos. Conforme mencionado anteriormente a restrição da dilatação é um dos principais fatores responsáveis pela tensão no material. Com essa mudança podemos reduzir as tensões nos tubos da extremidade do trocador que normalmente são os mais afetados pela variação de temperatura.

Nesse trabalho iremos representar essa mudança da geometria com um simples corte, porém isso pode resultar em redução da resistência do trocador para esforços diversos. Existem soluções mais elegantes que melhoram a dilatação térmica no componente sem reduzir a resistência do mesmo, que não é o foco desse estudo.

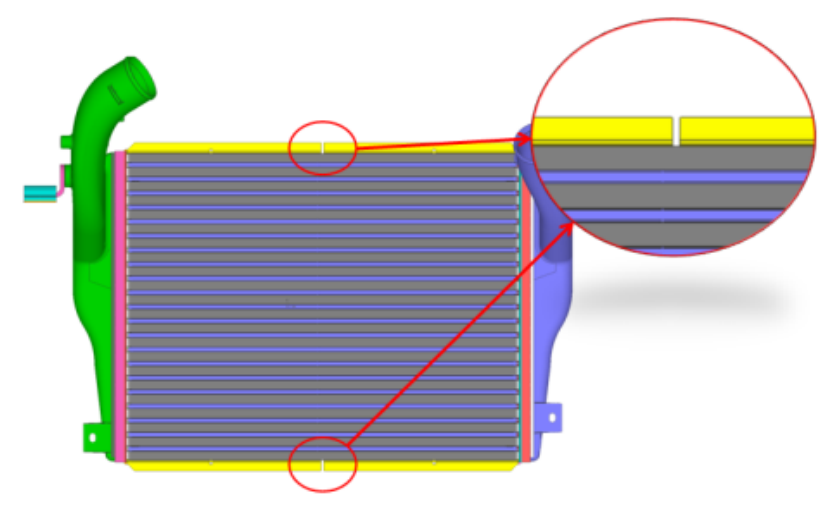

Figura 16 - Geometria da com o detalhe da modificação.

Com a nova geometria tem-se um novo perfil de tensões. Onde também é possível ver a concentração a maior variação de tensão no tubo 20 que é do lado da entrada.

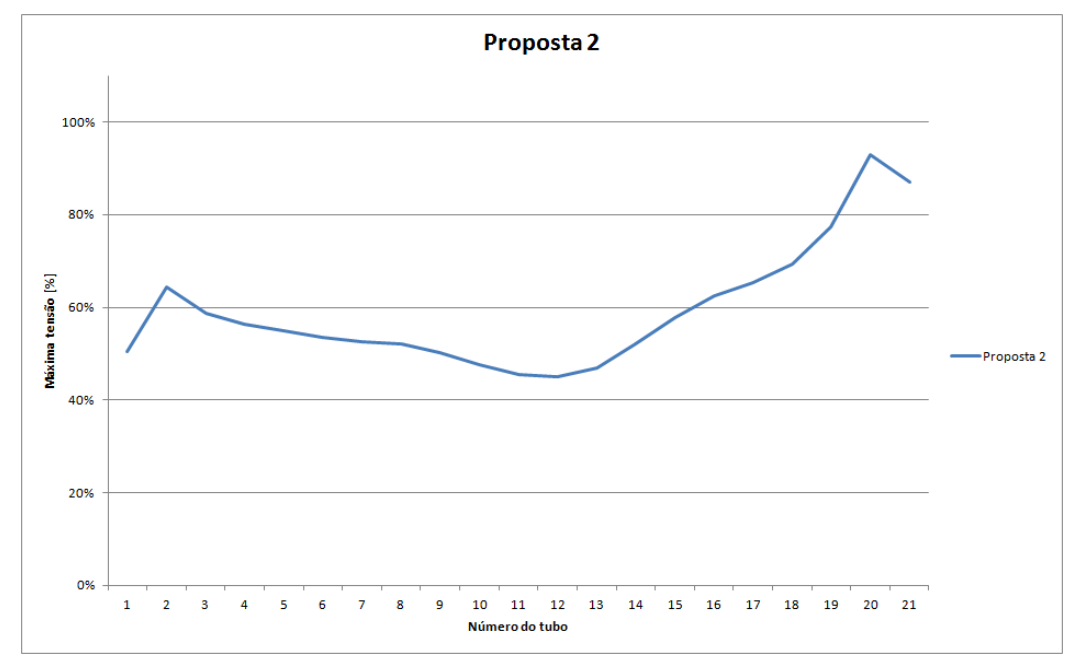

Figura 17 - Gráfico da variação de tensão proposta 2. 


\subsubsection{Proposta 3 - Aumento de espessura na parede do tubo.}

Com o aumento da espessura conseguimos reduzir consideravelmente os níveis de tensões na secção do tubo, esta modificação irá aumentar a vida útil da peça. Porem esta alteração ira restringir a dilatação térmica na região que se mostrou um dos principais fatores da falha analisada.

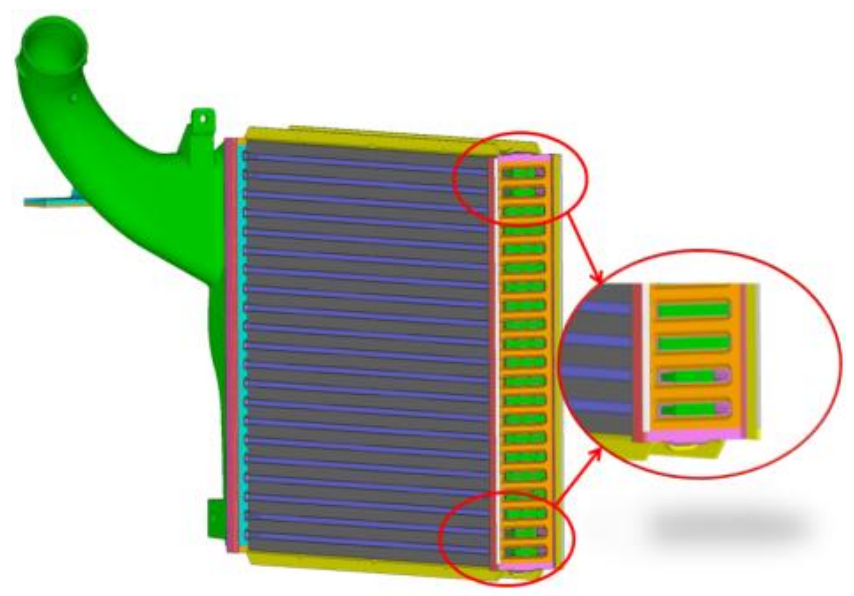

Figura 18 - Detalhe da modificação da proposta 3.

A variação de tensão encontrada no caso da terceira proposta apresenta um perfil onde a maior variação está nos tubos 1 e 21 conforme apresentado no gráfico (Figura 19).

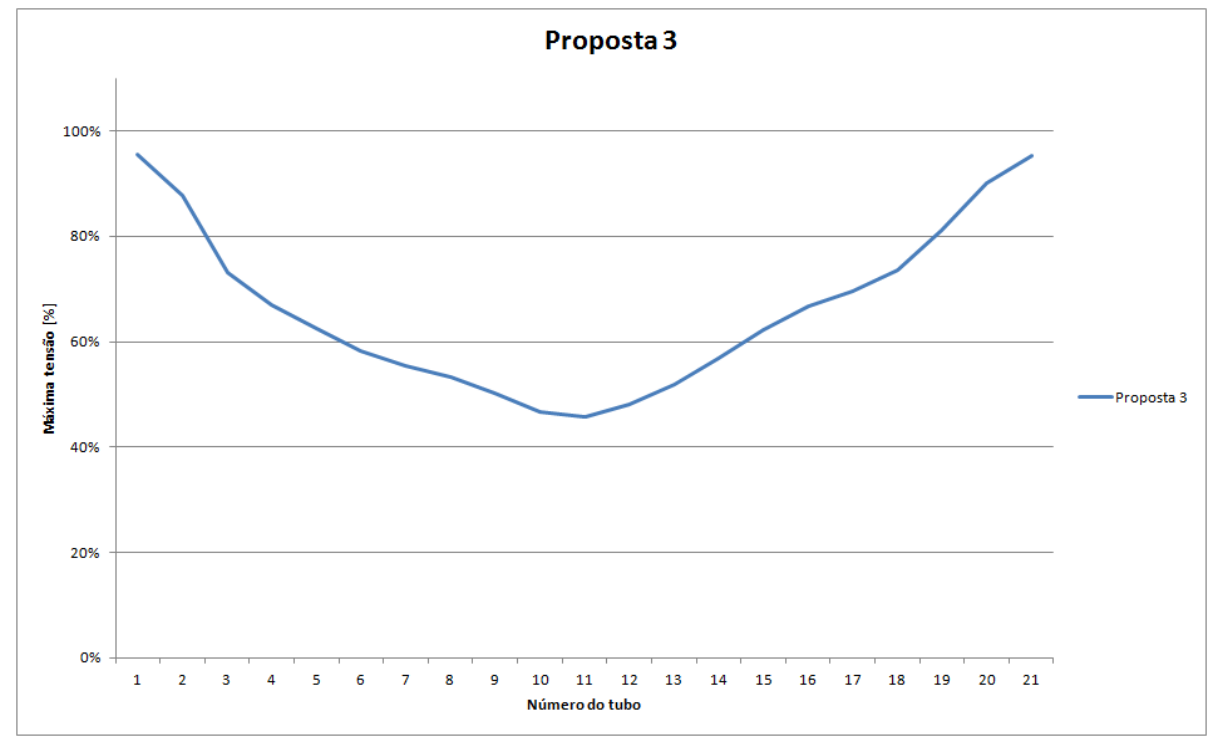

Figura 19 - Gráfico da variação de tensão proposta 3.

3.2.3. Proposta 4-Permitir a dilatação térmica nos tubos e adição de reforços na região dos tubos (Proposta 2 + Proposta 3).

Essa proposta tem com o intuito permitir a dilatação térmica e aumentar a área da secção reduzindo ao máximo os esforços nos tubos juntando as duas propostas anteriores. 


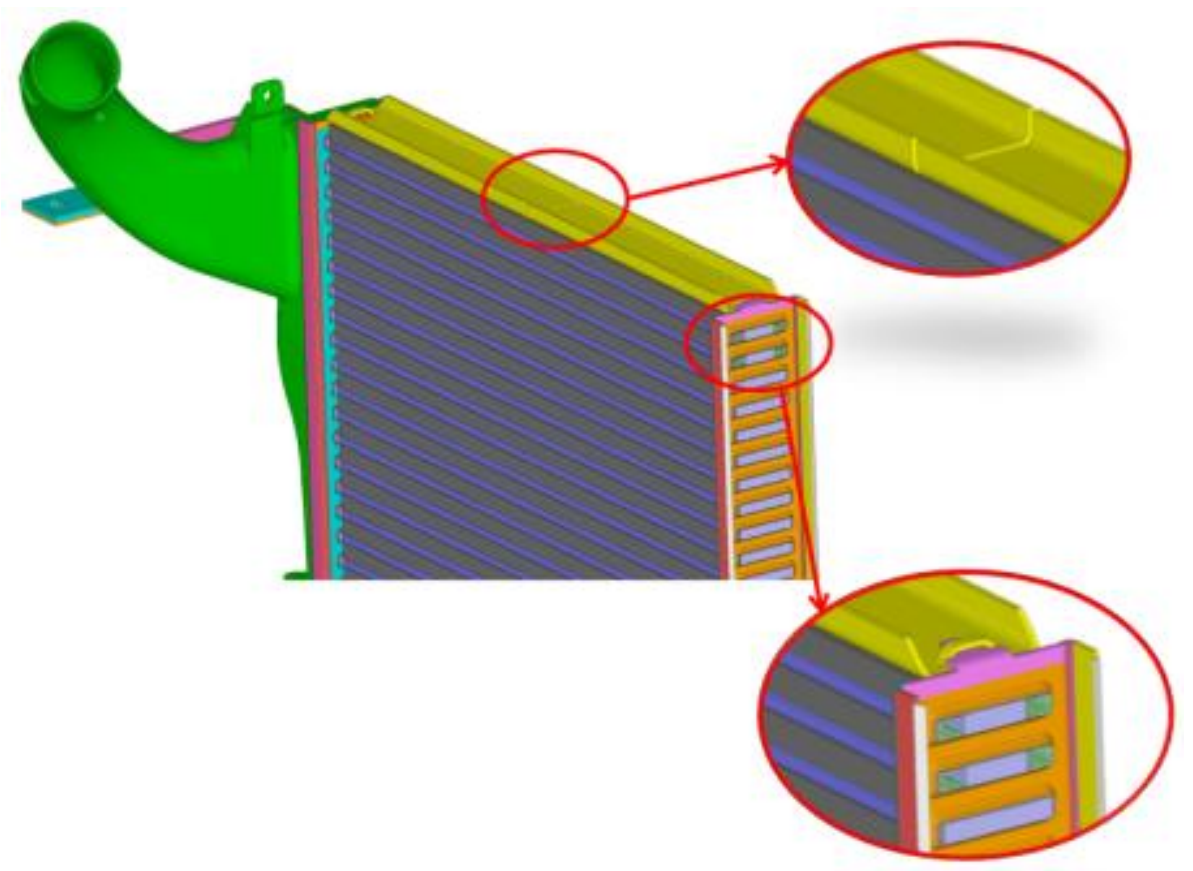

Figura 20 - Detalhe da modificação da proposta 4.

Para a proposta 4 é possível ver que as tensões mais altas estão agora nos tubos 1 e 2 do lado quente (Figura 21). Uma comparação de todos os resultados será apresentada a seguir.

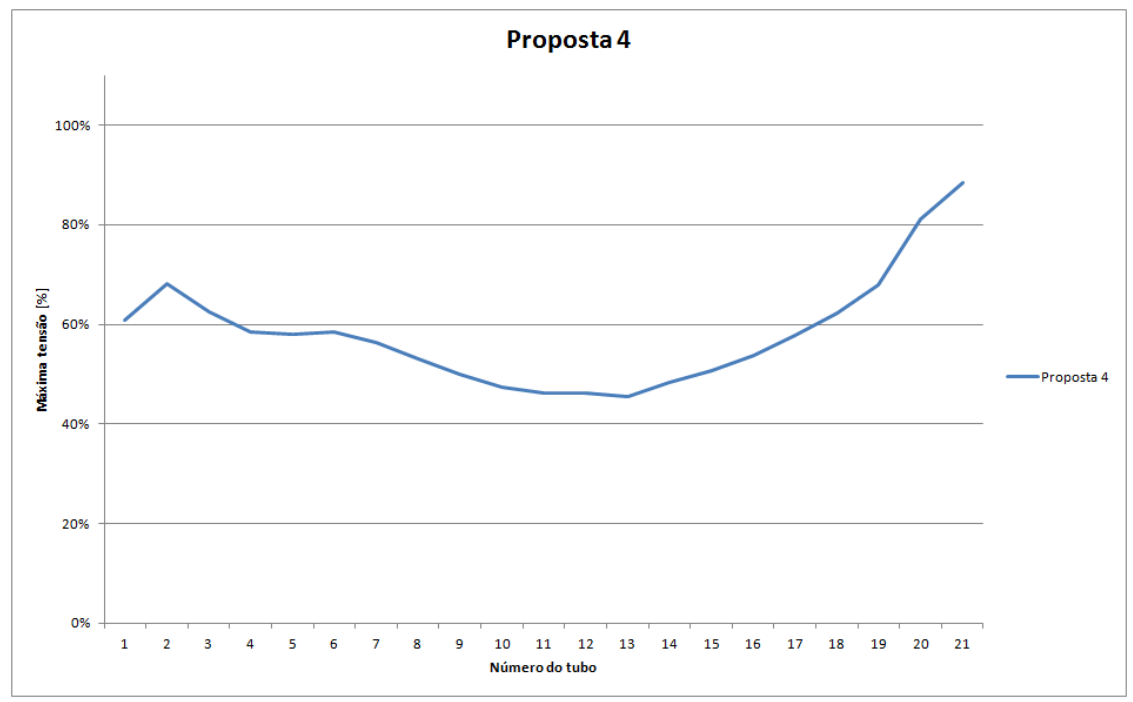

Figura 21 - Gráfico da variação de tensão proposta 4.

Através de uma simulação CFD foram obtidos os perfis de temperatura em cada ponto da malha (Figura 18). Com isso obtem-se o gradiente de temperatura em cada instante de tempo para o calculo das tensões para cada proposta apresentada anteriormente. 


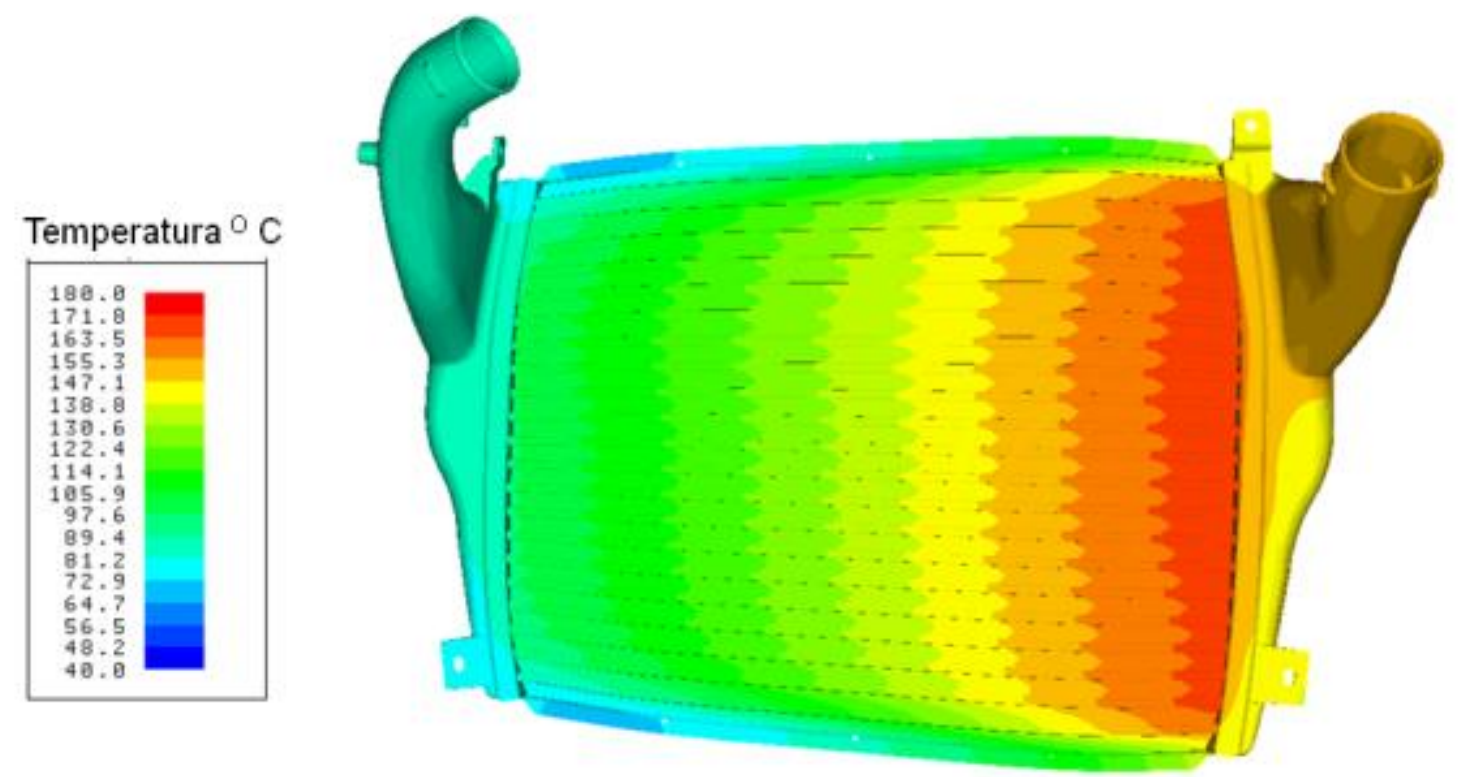

Figura 22 - Perfil de temperatura de acordo com a simulação CFD.

A partir dos valores de temperatura calculados na simulação CFD pode-se definir a variação de tensão em cada ponto do trocador de calor e verificar onde ocorrem as maiores tensões que são apresentados no item 3.4 (Figuras 22, 23, 24 e 25).

\subsection{Testes de bancada.}

O teste de ciclo de temperatura foi realizado seguindo o perfil de temperatura apresentado anteriormente (Figura 13) o qual foi subdividido em fases quente e fio para o fluxo de ar interno. Na vazão de ar externo o fluxo de ar foi constante. Foi inicialmente realizado alguns ciclo com o intuito que estabilizar as tensões nos tubos antes de realizar a coleta de dados. Os dados foram coletados por 2 horas. A fixação da peça na bancada foi conforme montagem do módulo e condições de contorno da simulação (Figura 24) para que tenhamos uma representatividade entre os dois resultados.

Foram medidas as variações de tensões nos três primeiros tubos, que de acordo com a simulação apresentaram os maiores valores de tensão, tanto para o lado da entrada do ar, que apresenta os valores maiores, quanto para o lado da saída do ar.

Os valores obtidos foram relacionados com a simulação com o intuito de verificar se o comportamento do componente apresenta as mesmas características que na simulação. 


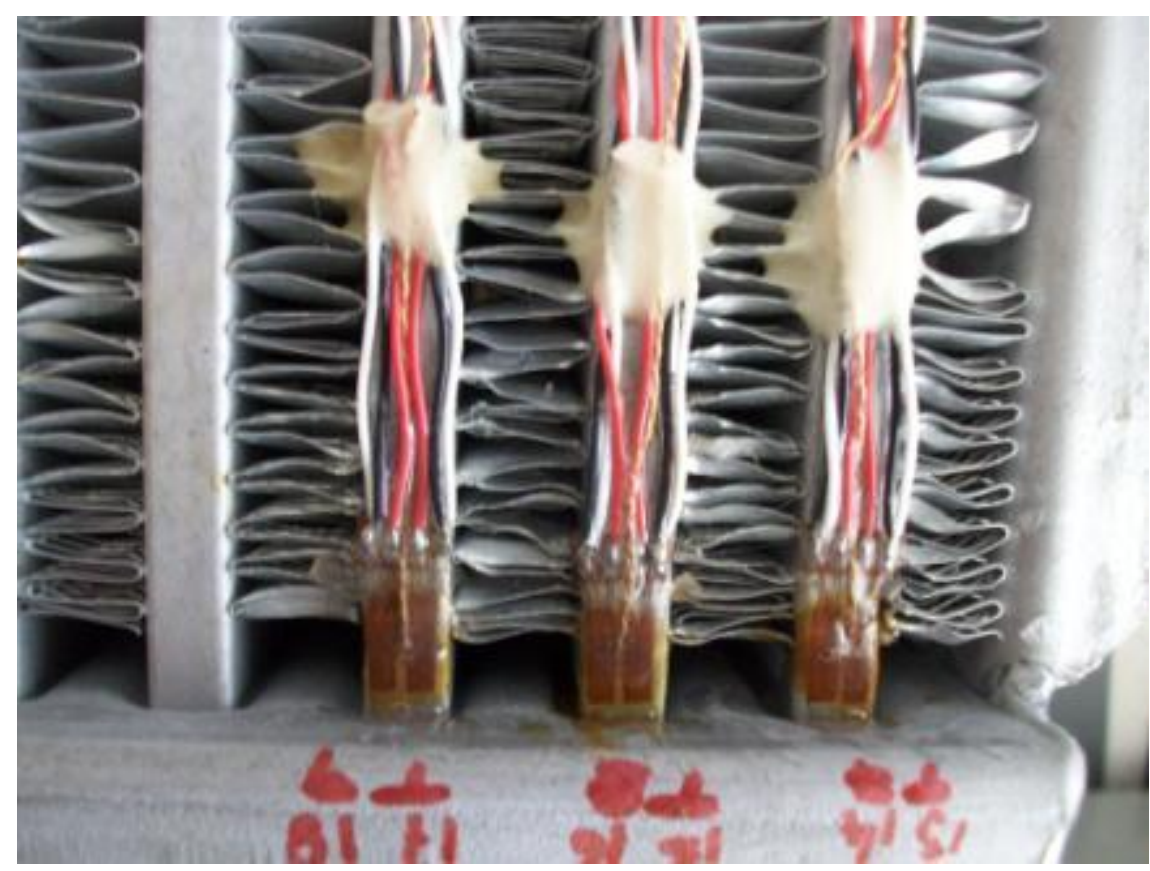

Figura 23 - Foto da região instrumentada com strain-gages.

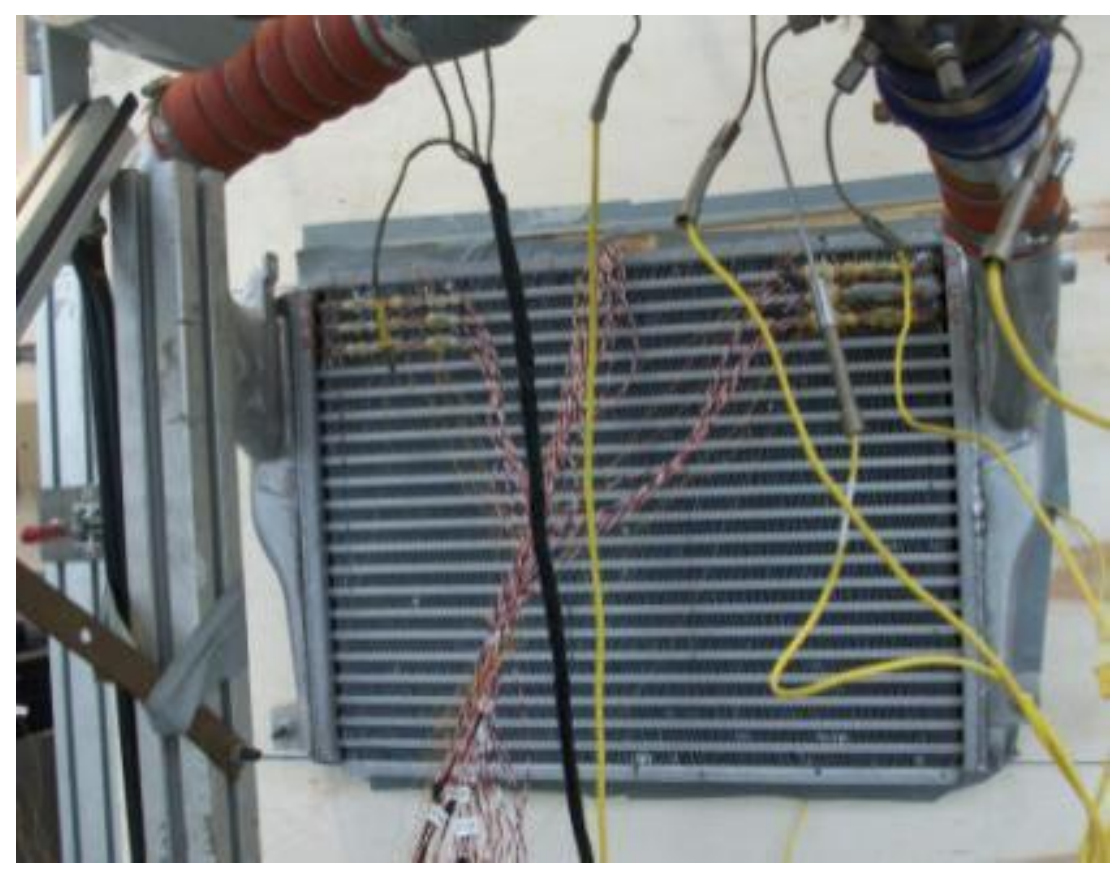

Figura 24 - Foto da montagem da peça instrumentada em bancada de teste.

Com o uso de uma câmera térmica mediu-se as temperaturas em cada ponto do trocador de calor (Figura 25) e comparamos com os valores obtidos através da simulação numérica. 


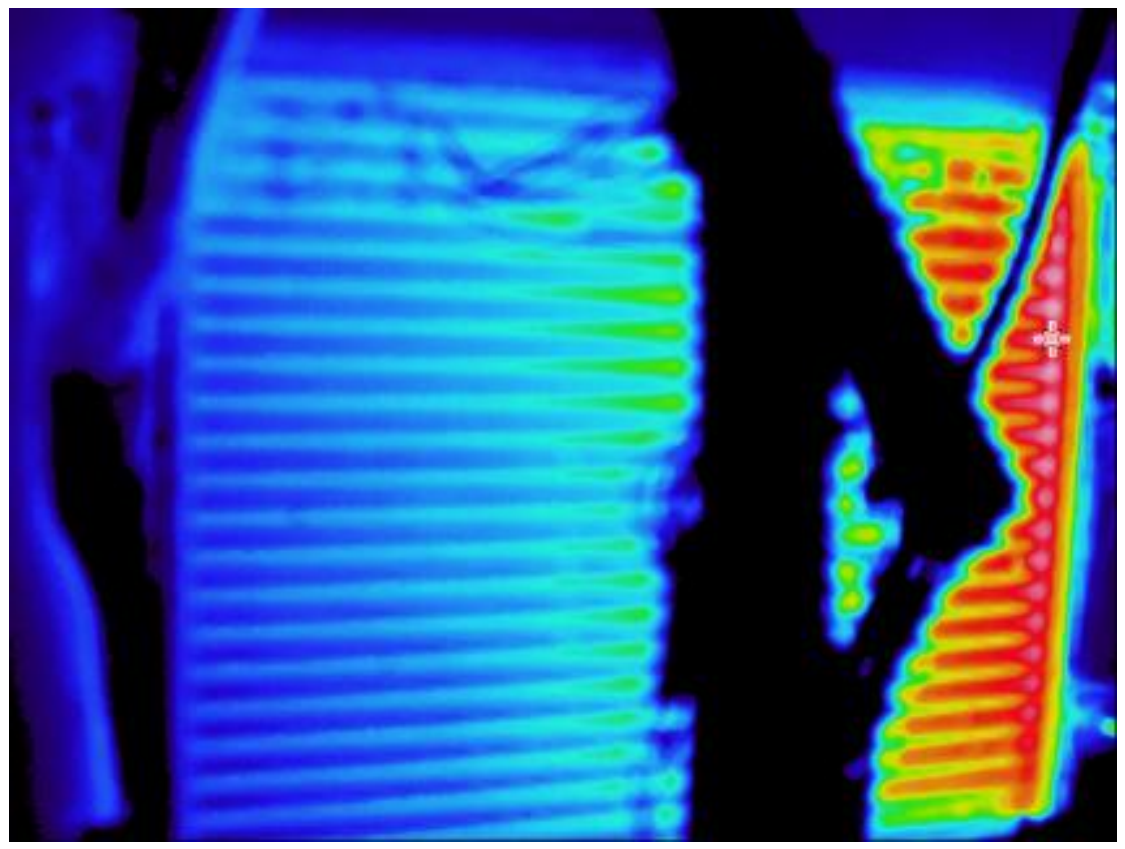

Figura 25 - Perfil de temperatura no teste de bancada.

3.4 Analise dos resultados.

Comparando os valores da proposta 1 com o da proposta 2 vê-se uma redução significativa de tensão (Figura 26) que coresponderá uma maior vida útil.

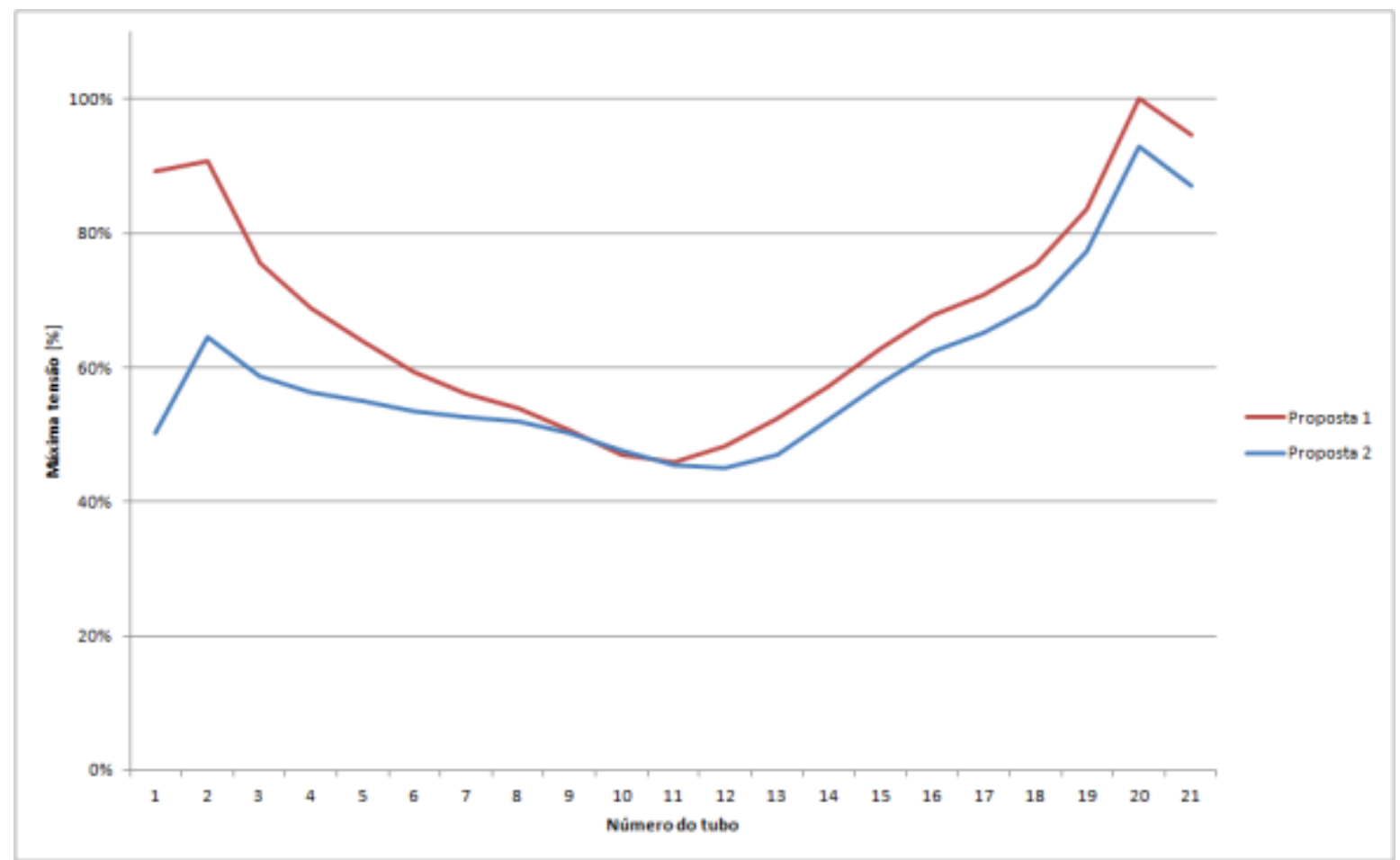

Figura 26 - Comparativo do perfil da variação de tensões máximas encontradas na proposta 1 e proposta 2. 
Comparando os valores da proposta $1 \mathrm{com}$ o da proposta 3 vê-se uma redução das tensões (Figura 27), porem devido a restrição que causamos na dilatação térmica isso provoca um aumento nas tensões dos tubos 1 e 21.

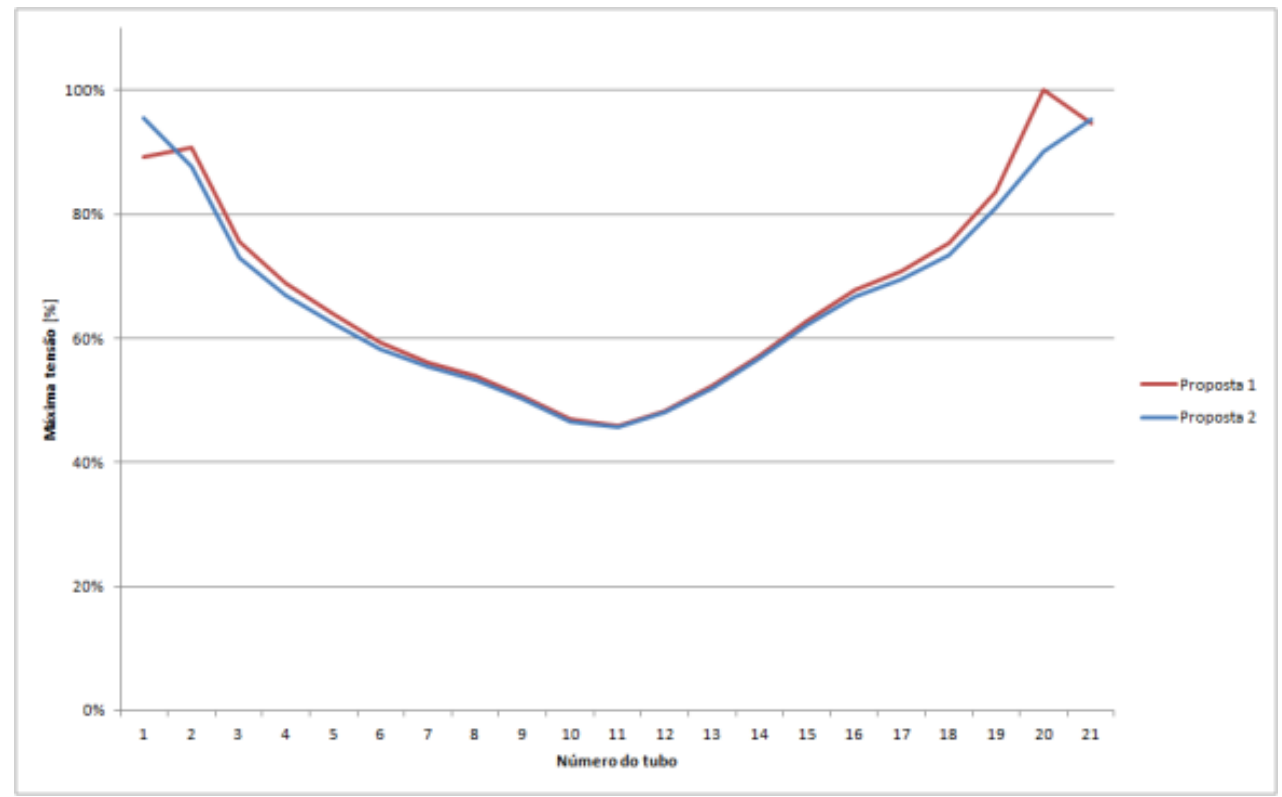

Figura 27 - Comparativo do perfil da variação de tensões máximas encontradas na proposta 1 e proposta 3 .

No gráfico a seguir (Figura 28) é possível verificar que as tensões nos tubos 20 e 21 da proposta 4 são muito abaixo das que se encontrou na proposta 1.

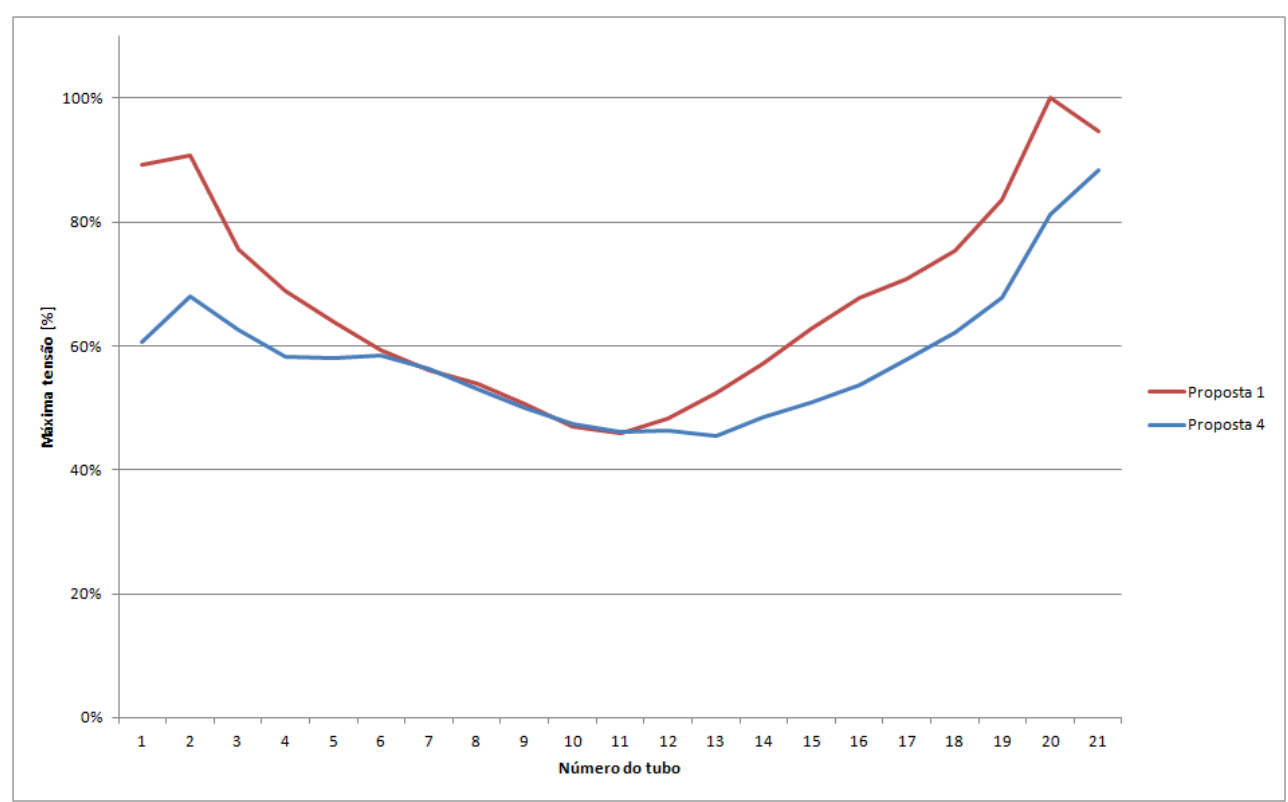

Figura 28 - Comparativo do perfil da variação de tensão no maior ponto do trocador nas propostas 1 e 4 . 
Abaixo temos uma tabela comparando todos os valores obtidos na simulação onde 100\% é a maior variação de tensão encontrada na proposta 1.

\begin{tabular}{|l|c|c|c|c|}
\hline \multirow{2}{*}{ Variant2 } & \multicolumn{3}{|c|}{ Tubo 20,21 } \\
\cline { 2 - 5 } & \multicolumn{2}{|c|}{ Entrada } & \multicolumn{2}{c|}{ Saída } \\
\cline { 2 - 5 } & frontal & motor & frontal & motor \\
\hline Proposta \#1 & $83 \%$ & $100 \%$ & $68 \%$ & $87 \%$ \\
\hline Proposta \#2 & $77 \%$ & $90 \%$ & $62 \%$ & $80 \%$ \\
\hline Proposta \#3 & $87 \%$ & $95 \%$ & $69 \%$ & $80 \%$ \\
\hline Proposta \#4 & $60 \%$ & $68 \%$ & $45 \%$ & $57 \%$ \\
\hline
\end{tabular}

Tabela 1 - Comparativo das tensões maiores tensões nos tubos.

Abaixo temos o gráfico das maiores tensões encontradas nos tubos. Pode-se ver que as maiores variações de tensão para as propostas 1 e 2 se encontram nos tubos 20 e para as propostas 3 e 4 nos tubos 21 , onde temos os reforços nos tubos.

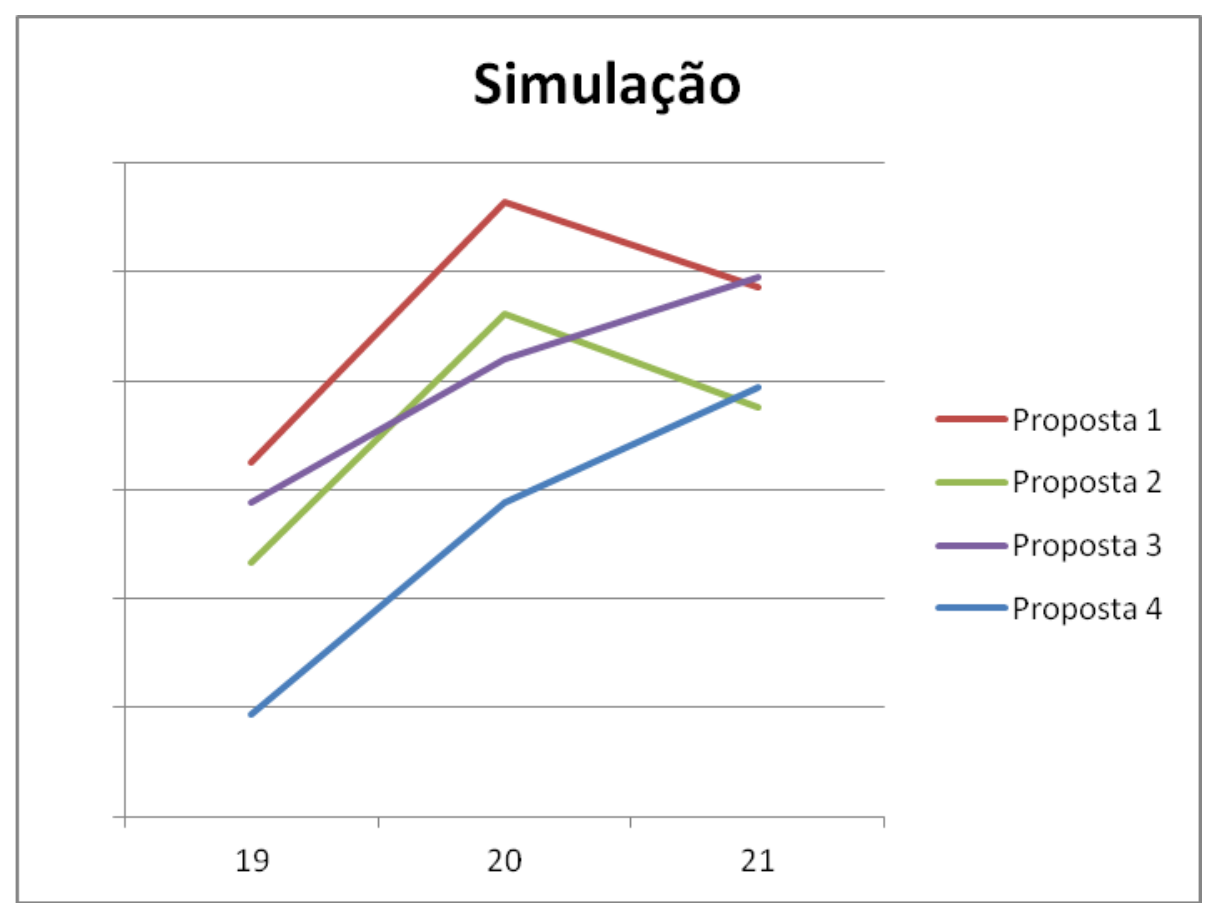

Figura 29 - Perfil de tensões obtido via simulação numérica nos tubos 19, 20 e 21.

A variação de tensão nos tubos do trocador medido em teste de bancada apresenta um comportamento similar ao simulado. 


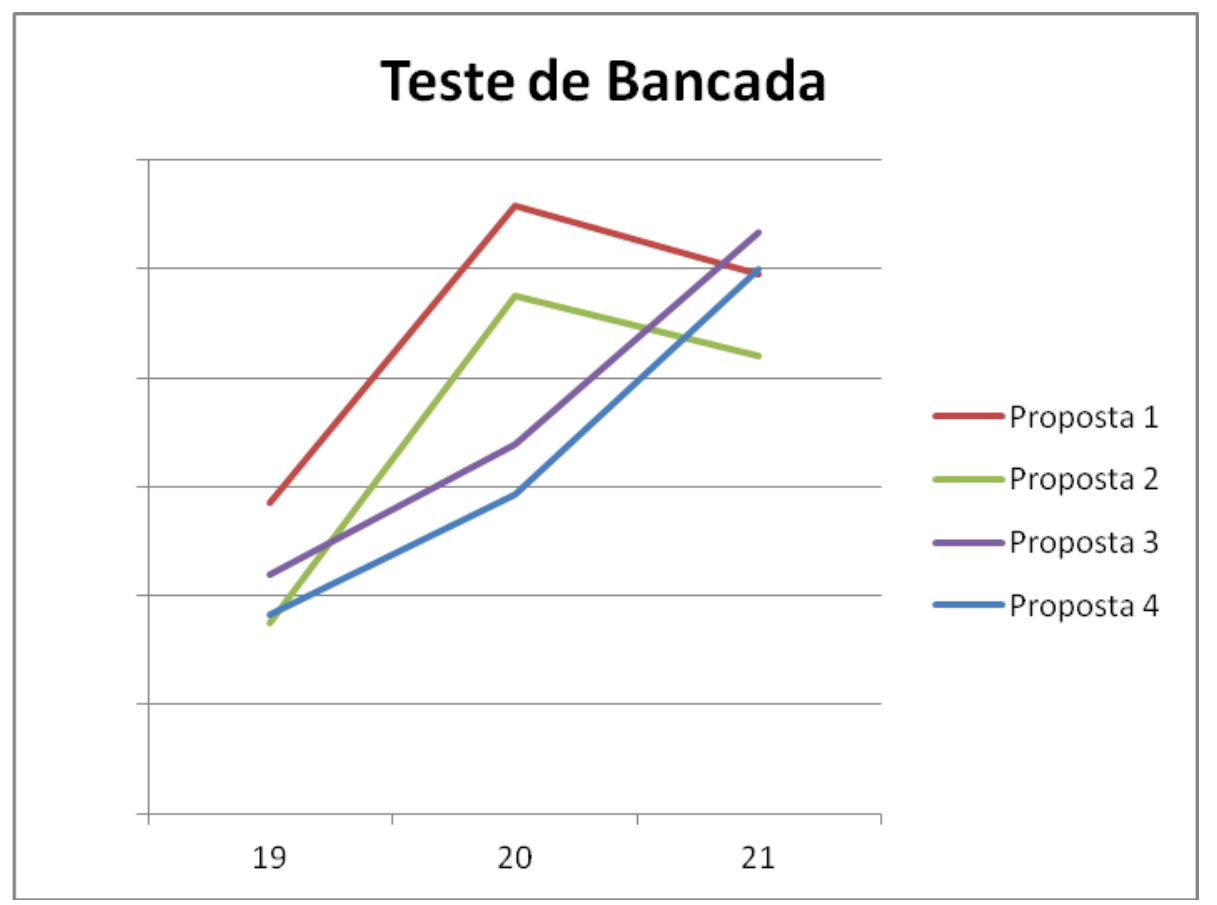

Figura 30 - Perfil de tensões obtido em bancada nos tubos 19, 20 e 21 .

\section{CONCLUSÃO}

Comparando os resultados obtidos experimentalmente com os resultados obtidos pela simulação conseguimos evidenciar que temos uma convergência dos resultados (Figuras 29 e 30), indicando boa assertividade neste método. A confiabilidade se comprova no resultado de testes realizados no veículo em uma determinada aplicação.

A estimativa de vida útil do componente poderia ser definida através de uma curva ou análise de Weibull (B10), o que poderia ser objeto de estudo para um futuro trabalho, porem temos como escolher a proposta mais viável, seja do ponto de vista de manufatura ou econômico. Devido ao comportamento exponencial do diagrama (Figura 9) pode-se ver que uma redução de $32 \%$ na variação de tensão no componente resultaria em um aumento significativo na vida do mesmo.

Assim, conseguimos gerar propostas de design e material para evitar quebras por fadiga causada pelo choque térmico, reduzir o tempo e custo de desenvolvimento e validação de um produto, explorar e/ou validar ideias para otimização e redução de custos de um produto. Estes fatores associados se tornam fundamentais em uma indústria cada vez mais competitiva, focada em qualidade, inovadora e sem margem para erros. 
Para esclarecimentos adicionais, contatar:

João Paulo Sparvoli Cardoso da Silva

Estrada dos Fernandes, 510, 07400-970 Arujá, São Paulo, Brasil

Telefone: +55 11 4589-0940,

joao.sparvoli@br.mahle.com

\section{Referência}

[1] Miyauchi, E. T.; De Lima, R. Q.; Erberelli, D. P. - Soluções de Gerenciamento Térmico Para Redução do Consumo de Combustível em Veículos Comerciais SIMEA - 2014

[2] Alvarenga Jr, A. - Avaliação Experimental dos Efeitos da Fadiga Térmica nas Propriedades Mecânicas de um Aço Inoxidavel Austenítico - UFMG - Belo Horizonte -2006

[3] Araújo Jr, P. E. - Influência de Solicitações Térmicas na Resistência à Fadiga do Aço Aisi 304I - PUCMinas - Belo Horizonte - 2005

[4] Concer, D. - Revisão de Fadiga Térmica de Matrizes para Injeção de Alumínio Sob Pressão Utilizando a Equação de Basquin e Elementos Finitos - UFP Curitiba - 2011 